\title{
About This Issue
}

The six articles in this omnibus issue address a broad spectrum of topics in contemporary research and scholarship relating to the design, planning, and management of land. Two articles address environmental justice as it affects and is affected by landscape architecture. Two articles focus on the effectiveness of strategies for online learning and service learning: one focuses on instruction in landscape history and another examines a design studio seeking to activate community revitalization in underserved and socially vulnerable neighborhoods in Houston, Texas. In the latter case, the authors examine the integrated use of landscape performance metrics and community engagement strategies. Three articles, set in the United States, Belgium and India, focus on approaches to cultural landscape planning and design.

In her article, titled "Environmental Justice as Justification for Landscape Architectural Design,” Hyejung Chang identifies the moral imperative for landscape architecture to embrace environmental justice. She examines divergent principles of justice that are relevant to codes of professional and environmental ethics as they apply to decision-making processes in landscape architecture. She presents frameworks and principles of environmental justice applicable to landscape design theory and practice. Marccus Hendricks, Galen Newman, Siyu Yu, and Jennifer Horney report on a service-learning design studio that combined diverse community engagement strategies with use of landscape performance metrics in developing and evaluating neighborhood design strategies for a Houston community. Their article reports on the successful integration of these strategies in creating designs to increase neighborhood resiliency in the face of a high susceptibility to flood inundation.
Galen Newman, Benjamin George, Dongying Li, Zhihan Tao, Siyu Yu, and Ryun Jung Lee evaluate the use of online learning as a means of delivering a high-enrollment introductory landscape history class to students in multiple disciplines. They report that although online learning increases the flexibility of course scheduling, enhances student self-motivation, and removes geographic barriers for instructional delivery, technical challenges and the limited amount of student-teacher/student-student interaction may currently limit its capabilities in landscape architecture.

Within the realm of articles on cultural landscape, Amita Sinha's examines on the ghats (steps and landings) on the River Ganga in Varanasi, India. She discusses the dilemma of cultural practices that celebrate the River Ganga as an archetypal symbol of purity and capable of cleansing moral and physical dirt while contributing to local point source pollution on the ghats. Drawing on Kevin Lynch's insights on the meanings of waste in explaining the contradictory traditional religious and modern secular views of the river's ability to deal with waste, Sinha proposes a sustainable waste management model on the ghats that would contribute to the health of the heavily polluted river and the people engaged with it.

Ole Sleipness and Caroline Lavoie examine the disappearance from the public's collective memory of the canal and water system of Logan, Utah. Using design as a research method and driven by Pierre Nora's concepts of milieux de mémoire and lieux de mémoire, they explain how people may find landscape meaning across time and cultures.

Finally, Sylvie Van Damme explores the development of landscape narratives. Triangulating among a qualitative interpretation of landscape 
literature, expert interviews of key informants, and a content analysis of professional practice in Flanders (northern Belgium), she identifies seven landscape narratives in the practice of landscape architecture.

Daniel Nadenicek

David Pitt 